\title{
SUSTAINABILITY RESEARCH: THEMES AND METHODS
}

\author{
Special Issue - Editorial Comment
}

XXI century shows several financial, social and environmental challenges, therefore making sustainability an important subject of research and study. More than 30 years since the Brundtland Report was published, which was considered one of the most important milestones for the propagation of sustainability studies, several researches in this field are being developed.

The Journal of Environmental Management \& Sustainability (GeAS Journal) is a scientific Brazilian publishing which the mission is to contribute to the dissemination of the Environmental Management \& Sustainability knowledge and it's three dimensions (environmental, social and economic). Since 2or2, twenty-one editions of the journal have been published.

This special edition of the GeAS Journal was arranged with the support of the National Council for Scientific and Technological Development $(\mathrm{CNPq})$, through the call CNPq/ CAPES number 18/2018 - Editorial Program.

In this context, we present in the journal a group of to articles which brings unpublished contributions to research themes and methods in the field of sustainability, written by foreign researchers from institutions of different countries, such as: Suffolk University, United States; Leuphana University, Germany; University of Lisbon, Portugal; ISG International Business School, France; Millennium Project, Spain; University of La Frontera, Chile; Universidade Autônoma de Lisboa [Autonomous University of Lisbon], Portugal; University of Barcelona, Espanha; University of Porto, Portugal; University of Central Florida, United States; as well as Brazilian researchers from several regions of the country: University of São Paulo (USP-SP); Pontifical Catholic University of Campinas (PUC-Campinas); Federal University of Santa Maria, (UFSM - RS); Nove de Julho University (UNINOVE - SP); Pontifical Catholic University of São Paulo (PUC-São Paulo - SP); Millennium Project Brazil; University of São Paulo (USP - Ribeirão Preto); Federal University of Technology - Paraná (UTFPR - PR); São Paulo State University (UNESP - SP).

Sustainability is a field of study that permeates through several areas of knowledge, from studies in cities, urban planning, administration, environmental and biological sciences to engineering branches. It is a transdisciplinary theme and it allows applied research in hard and soft sciences.

In the field of Administration, the research on sustainability emphasizes the necessity for the organizations to upgrade their supply chain management and for the development of social environmental responsibility politics. In other areas of knowledge, the studies focus on developing new materials, diffusing a cleaner energy mix and identifying new economic theories.

Given this scenario, some articles in this special edition highlight that, regardless of the progress in sustainability research in the last few decades, new methods and methodologies of research need to be applied to understand the complexity of human life. The researchers Fritjof Capra and Pier Luigi Luisi and their work The Systems View of Life reassures this perspective by exposing that the current environmental issues are highly complex and they are not liable for being understood in an isolated way, demanding a new paradigm to understand the world.

Still from the point of view of the methodology, this edition brings a scientific production vision about sustainability in the last 20 
years, concluding the theme is still rising and indicating there is a research gap especially in themes related to green technology, sustainable innovation and public policy. That shows the importance of this science to the academy and the society.

Referring to environmental matters, this edition also shows an important study that purposes indicators of sustainability in the environmental, spatial, cultural, social and economic dimensions and validates a research methodology in the context of Sustainable Development Reserve of Ribeirinha Community in Brazilian Amazon. Besides, there are also methodological studies based on the Grounded Theory about climate change and urban participative management for sustainable development, since they show new structures of governance to deal with environmental challenges.

The works that are present here speak of other relevant themes for sustainable development, as methods to manage plastic waste on the Commodity Chain, geophysic methodologies in the investigation of underground contamination and, also, a work that speaks of applied research to increase the production of biogas for the fortification of renewable energy mix.

The solutions for sustainable development go through innovation and the capacity for planning ahead. Therefore, this edition shares a work about patents, which contribute to the propagation of studies and applications of network theory for interorganizational innovations. And, sticking to the solution subject, we present a work that speaks of research methods in strategic perspective, emphasizing the importance of research methodologies for visualizing future scenarios to deal with a series of global challenges.

We would like to thank the contribution of all the professionals involved for their dedication to elaborate this edition: editors, evaluators, members of the Editorial Council and the Scientific Committee, normative revisors and editorial assistants. We believe we are presenting to the scientific community an important work, which would not be possible without the contribution of the authors who willingly accepted our invitation to share their research. To these authors, great academics and researchers, we give our special thanks.

Good reading for everybody!

GUEST EDITORS

\section{Prof. Dr. Claudia Terezinha Kniess}

Doctor in Materials Science and Engineering at Federal University of Santa Catarina. Professor at University of Taubaté (UNITAU), Taubaté, Brazil E-mail:kniessc1@gmail.com

\section{Prof. Dr. Diego de Melo Conti}

Doctor in Business Administration at Pontifical Catholic University of São Paulo, Professor at Nove de Julho University(Uninove), São Paulo, Brazil E-mail: diegoconti@uol.com.br 